\title{
Evaluation of Power Density for Three Phase Double-Sided Axial Flux Slotted PM Generator
}

\author{
S. Asghar Gholamian \\ Faculty of Electrical and Computer Engineering, Babol University of \\ Technology, Babol, Iran. \\ Emails: gholamian@nit.ac.ir
}

\begin{abstract}
There are two topologies for slotted double-sided axial flux permanent magnet generator (AFPG). Choosing an AFPG with high power density is an important parameter in applications. Hence, power density Evaluation between double-sided AFPM generators topologies is necessary. In this paper, the sizing equations of axial flux slotted one-stator-two-rotor (TORUS) and two-stator-one-rotor (AFIR) type PM generators is presented and comparison of the TORUS and AFIR topologies in terms of power density is illustrated. Finally a high power double-sided AFPG is introduced in the paper.
\end{abstract}

\section{KEYWORDS}

Axial flux, Generator, Power density, PM

\section{INTRODUCTION}

The BLDC generator is a kind of permanent-magnet (PM) generator that has permanent magnets inside the machine. In conventional machines, the air gap flux density has normally radial direction; in AFPGs, the air gap flux density presents mainly axial direction. In general, AFPGs exhibit an axial length much smaller than the length of a conventional generator of the same rating [1-4].

Two topologies of slotted double-sided AFPGs are axial flux slotted one-stator-two-rotor (TORUS) and two-stator-one-rotor (AFIR). Two AFPGs and their acronyms are selected TORUS-S (Axial flux slotted external rotor internal stator PM stator) and AFIR-S (Axial flux slotted internal rotor external stator PM generator) for detailed analysis [5-7].

The stator cores of the machine are formed by tape wound core with a lap and short-pitched poly phase AC winding located in punched stator slots. The rotor structure is formed by the axially magnetized $\mathrm{NdFeB}$ magnets $[1,6,10-13]$. 


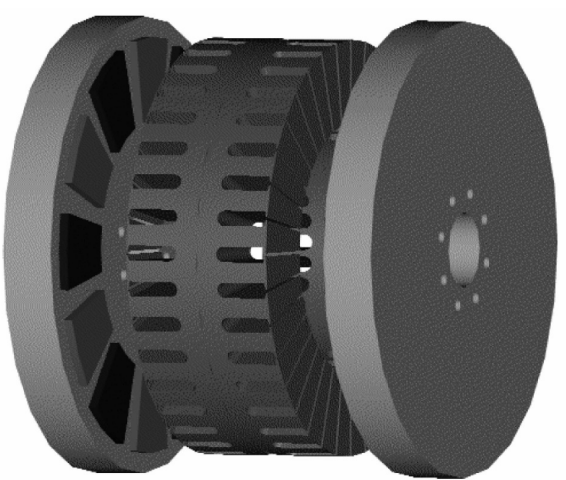

(a)

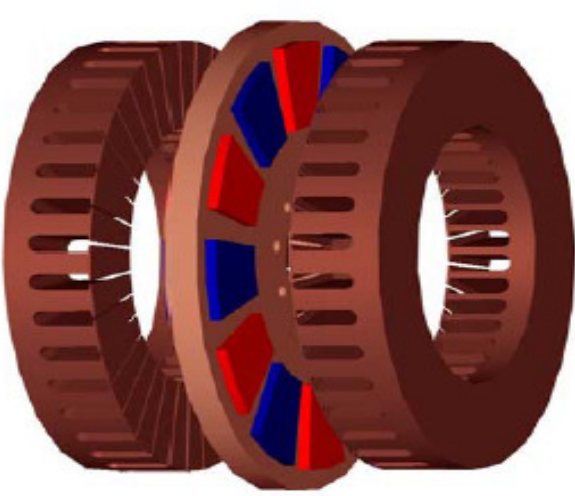

(b)

Figure1. Axial flux slotted (a) one-stator-two-rotor TORUS-S type (b) two-stator-one-rotor AFIR-S type

Figure 1 are illustrated the topologies used in this article. Figure 2 is also illustrated Flux directions of AFIR and TORUS slotted topologies.

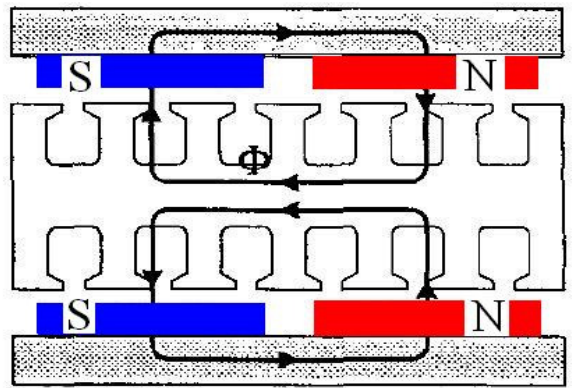

(a)

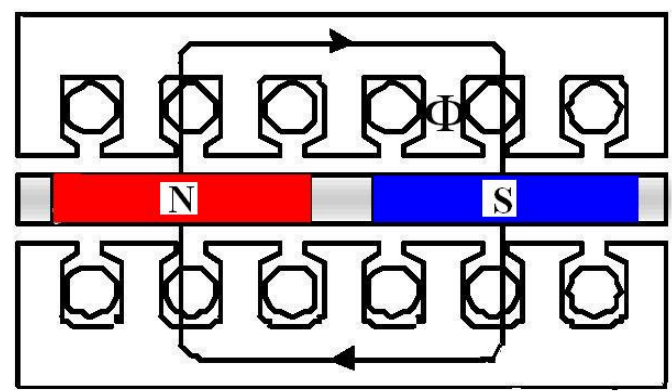

(b)

Figure2. One pole pair of the (a) TORUS-S [6] (b) AFIR-S [5]

Selecting double-sided AFPGs with high power density is an important parameter. So, comparison of power density between different topologies of double-sided AFPGs seems to be necessary $[1,3,6-8]$.

Increasing the air gap length, maximum power density will change in AFPGs. In Section2, the generalized sizing approach for TORUS-S and AFIR-S types PM generators is briefly discussed. The power density comparisons and some results of TORUS-S and AFIR-S topologies are presented in Section 4.

\section{SIZING EQUATION of AFPGs}

In general, if stator leakage inductance and resistance are neglected, the output power for axial flux permanent magnet generator can be expressed as

$$
P_{\text {out }}=\frac{m}{m_{1}} \frac{\pi}{2} K_{e} K_{p} K_{i} A B_{g} \eta \frac{f}{p}\left(1-\lambda^{2}\right)\left(\frac{1+\lambda}{2}\right) D_{o}^{3}
$$

Where, $m_{l}$ is number of phases of each stator, $m$ is number of phases of the machine, $K_{p}$ is termed the electrical power waveform factor, $K_{e}$ is the EMF factor which incorporates the winding distribution factor $K_{w}$ and the per unit portion of the total air gap area spanned by the salient poles of the machine (if any), $K_{i}$ is the current waveform factor, $A$ is the electrical loading, $\eta$ is machine 
efficiency, $N_{p h}$ is the number of turn per phase, $B_{g}$ is the flux density in the air gap, $f$ is the converter frequency, $p$ is the machine pole pairs, $\lambda$ is the diameter ratio for AFPG defined as $D_{i}$ $/ D_{o}, D_{o}$ is the diameter of the machine outer surface, $D_{i}$ is the diameter of the machine inner surface[1,3-6].

The machine power density for the total volume can be defined as

$$
\mathrm{P}_{\mathrm{den}}=\frac{\mathrm{P}_{\text {out }}}{\frac{\pi}{4} \mathrm{D}_{\text {tot }}^{2} \mathrm{~L}_{\text {tot }}}
$$

Where, $D_{t o t}$ is the total machine outer diameter including the stack outer diameter and the protrusion of the end winding from the iron stack in the radial direction, $L_{t o t}$ is the total length of the machine including the stack length and the protrusion of the end winding from the iron stack in the axial direction [9-13].

\subsection{Sizing equations for the TORUS-S}

Sizing equation of axial flux permanent magnet TORUS type generator can easily be calculated according to above equations $\left[1,6\right.$, and 11]. The outer surface diameter $D_{o}$ can be written as

$$
\mathrm{D}_{\mathrm{o}}=\left(\mathrm{P}_{\text {out }} / \frac{\pi \mathrm{m}}{2 \mathrm{~m}_{1}} \mathrm{~K}_{\mathrm{e}} \mathrm{K}_{\mathrm{p}} \mathrm{K}_{\mathrm{i}} \mathrm{A} \mathrm{B}_{\mathrm{g}} \eta \frac{\mathrm{f}}{\mathrm{p}}\left(1-\lambda^{2}\right)\left(\frac{1+\lambda}{2}\right)\right)^{1 / 3}
$$

The generator total outer diameter $\mathrm{D}_{\text {tot }}$ for the TORUS-S generator is given by

$$
\mathrm{D}_{\mathrm{tot}}=\mathrm{D}_{\mathrm{o}}+2 \mathrm{~W}_{\mathrm{cu}}
$$

Where, $\mathrm{W}_{\mathrm{cu}}$ is the protrusion of the end winding from the iron stack in the radial direction. For the back-to-back wrapped winding, protrusions exist toward the axis of the machine as well as towards the outsides and can be calculated as

$$
\mathrm{W}_{\mathrm{cu}}=\frac{\mathrm{D}_{\mathrm{i}}-\sqrt{\mathrm{D}_{\mathrm{i}}^{2}-\left(2 \mathrm{AD}_{\mathrm{g}} / \mathrm{K}_{\mathrm{cu}} \mathrm{J}_{\mathrm{s}}\right)}}{2}
$$

Where, $\mathrm{D}_{\mathrm{g}}$ is the average diameter of the machine, $\mathrm{J}_{\mathrm{s}}$ is the current density and $\mathrm{K}_{\mathrm{cu}}$ is the copper fill factor. Note for the slotted topology machines the depth of the stator slot for slotted generators is $\mathrm{L}_{\mathrm{ss}}=\mathrm{W}_{\mathrm{cu}}$.

The axial length of the machine $\mathrm{L}_{\mathrm{e}}$ is given by

$$
\mathrm{L}_{\mathrm{e}}=\mathrm{L}_{\mathrm{s}}+2 \mathrm{~L}_{\mathrm{r}}+2 \mathrm{~g}
$$

Where, $L_{s}$ is axial length of the stator, $L_{r}$ is axial length of the rotor and $g$ is the air gap length. The axial length of the stator $L_{s}$ is

$$
\mathrm{L}_{\mathrm{s}}=\mathrm{L}_{\mathrm{cs}}+2 \mathrm{~L}_{\mathrm{ss}}
$$

The axial length of the stator core $L_{c s}$ can be written as

$$
\mathrm{L}_{\mathrm{cs}}=\frac{\mathrm{B}_{\mathrm{g}} \pi \alpha_{\mathrm{p}} \mathrm{D}_{\mathrm{o}}(1+\lambda)}{4 \mathrm{p} \mathrm{B} \mathrm{cs}}
$$

Where

$B_{c s}$ is the flux density in the stator core and $\alpha_{\mathrm{p}}$ is the ratio of average air gap flux density to peak air gap flux density.

The axial length of rotor $L_{r}$ becomes 
International Journal of Computer Science, Engineering and Applications (IJCSEA) Vol.1, No.6, December 2011

$$
\mathrm{L}_{\mathrm{r}}=\mathrm{L}_{\mathrm{cr}}+\mathrm{L}_{\mathrm{PM}}
$$

Also, the axial length of the rotor core $\mathrm{L}_{\mathrm{cr}}$ is

$$
\mathrm{L}_{\mathrm{cr}}=\frac{\mathrm{B}_{\mathrm{u}} \pi \mathrm{D}_{\mathrm{o}}(1+\lambda)}{8 \mathrm{p} \mathrm{B} \text { cr }}
$$

Where, $\mathrm{B}_{\mathrm{cr}}$ is the flux density in the rotor disc core, and $B_{u}$ is the attainable flux density on the surface of the PM.

The PM length $L_{P M}$ can be calculated as

$$
\mathrm{L}_{\mathrm{PM}}=\frac{\mu_{\mathrm{r}} \mathrm{B}_{\mathrm{g}}}{\mathrm{B}_{\mathrm{r}}-\left(\frac{\mathrm{K}_{\mathrm{f}}}{\mathrm{K}_{\mathrm{d}}} \mathrm{B}_{\mathrm{g}}\right)} \mathrm{K}_{\mathrm{c}} \mathrm{g}
$$

Where, $\mu_{\mathrm{r}}$ is the recoil relative permeability of the magnet, $B_{r}$ is the residual flux density of the $\mathrm{PM}$ material, $K_{d}$ is the leakage flux factor, $K_{c}$ is the Carter factor, $\mathrm{K}_{\mathrm{f}}=\mathrm{B}_{\mathrm{gpk}} / \mathrm{B}_{\mathrm{g}}$ is the peak value corrected factor of air gap flux density in radial direction of the AFPG generator. These factors can be obtained using FEM analysis [1], [6-10].

\subsection{Sizing equations for the AFIR-S}

Also, sizing equation of axial flux permanent magnet two-stator-one-rotor (AFIR) type generator can easily be calculated according to above equations [1, 6, and 11].

The outer surface diameter $D_{o}$ is obtained from (1).

$$
\mathrm{D}_{\mathrm{o}}=\left(2 \mathrm{P}_{\text {out }} / \frac{\pi \mathrm{m}}{2 \mathrm{~m}_{1}} \mathrm{~K}_{\mathrm{e}} \mathrm{K}_{\mathrm{p}} \mathrm{K}_{\mathrm{i}} \mathrm{A} \mathrm{B}_{\mathrm{g}} \eta \frac{\mathrm{f}}{\mathrm{p}}\left(1-\lambda^{2}\right)\left(\frac{1+\lambda}{2}\right)\right)^{1 / 3}
$$

The machine total outer diameter $D_{t o t}$ for the AFIR type machines is given as

$$
\mathrm{D}_{\mathrm{tot}}=\mathrm{D}_{\mathrm{o}}+2 \mathrm{~W}_{\mathrm{cu}}
$$

Where, $W_{c u}$ is the protrusion of the end winding from the iron stack in the radial direction and can be calculated as

$$
\mathrm{W}_{\mathrm{cu}}=\frac{(0.46-0.62) \mathrm{D}_{\mathrm{o}}}{\mathrm{p}}
$$

The axial length of the machine $L_{e}$ is

$$
\mathrm{L}_{\mathrm{e}}=\mathrm{L}_{\mathrm{r}}+2 \mathrm{~L}_{\mathrm{s}}+2 \mathrm{~g}
$$

Where, $L s$ is axial length of the stator, $L_{r}$ is axial length of the rotor and $g$ is the air gap length. The axial length of stator $L_{s}$ is

$$
\mathrm{L}_{\mathrm{s}}=\mathrm{L}_{\mathrm{cs}}+\mathrm{d}_{\mathrm{ss}}
$$

Where, $L_{c s}$ is the axial length of the stator core, and the depth of the stator slot for slotted machines $d_{s s}$ is

$$
d_{\mathrm{ss}}=\frac{D_{\mathrm{i}}-\sqrt{\mathrm{D}_{\mathrm{i}}^{2}-\left(2 \mathrm{~A} \mathrm{D} \mathrm{g}_{\mathrm{g}} / \alpha_{\mathrm{s}} \mathrm{K}_{\mathrm{cu}} \mathrm{J}_{\mathrm{s}}\right)}}{2}
$$

Where, $\alpha_{\mathrm{s}}$ is the ratio of stator teeth portion to the stator pole.

The axial length of the stator core $\mathrm{L}_{\mathrm{cs}}$ can be written as 
International Journal of Computer Science, Engineering and Applications (IJCSEA) Vol.1, No.6, December 2011

$$
\mathrm{L}_{\mathrm{cs}}=\frac{\mathrm{B}_{\mathrm{g}} \pi \alpha_{\mathrm{p}} \mathrm{D}_{\mathrm{o}}(1+\lambda)}{8 \mathrm{p} \mathrm{B} \text { cr }}
$$

Since there is no rotor core in rotor PM topologies, the axial length of rotor $L r$ is

$$
\mathrm{L}_{\mathrm{r}}=\mathrm{L}_{\mathrm{PM}}
$$

The PM length $L_{P M}$ can be calculated as

$$
\mathrm{L}_{\mathrm{PM}}=\frac{2 \mu_{\mathrm{r}} \mathrm{B}_{\mathrm{g}}}{\mathrm{B}_{\mathrm{r}}-\left(\frac{\mathrm{K}_{\mathrm{f}}}{\mathrm{K}_{\mathrm{d}}} \mathrm{B}_{\mathrm{g}}\right)} \mathrm{K}_{\mathrm{c}} \mathrm{g}
$$

\section{COMPAROSON of TORUS-S and AFIR-S}

Comparison of two different Double-sided axial flux slotted PM generators in terms of power density is accomplished for $14 \mathrm{Hp}$ output power, 4 poles and $60 \mathrm{~Hz}$ drive. In this comparison, other constant parameters of generators are tabulated in table1.

In AFPG generators, the air gap flux density and diameter ratio are the two important design parameters which have significant effect on the generator characteristics. Therefore, in order to optimize the generator performance, the diameter ratio and the air gap flux density must be chosen carefully.

Variation of power density as a function of air gap flux density and the diameter ratio for the AFIR-S and TORUS-S generators are shown in Figure3.

Table1. Constant parameters of generators in comparison

\begin{tabular}{|l|l|}
\hline Number of phases & 3 \\
\hline Slot fill factor & 0.80 \\
\hline Pole arc ratio & 0.75 \\
\hline flux density in stator & $1.55 \mathrm{~T}$ \\
\hline flux density in rotor & $1.55 \mathrm{~T}$ \\
\hline Efficiency & $90 \%$ \\
\hline Residual flux density of & $1.2 \mathrm{~T}$ \\
\hline
\end{tabular}

As can be seen from Figure $3 \mathrm{~b}$, the maximum power density occurs at $\mathrm{Bg}=0.528$ ( $\mathrm{T}$ ) and $\lambda=0.261$. In various air gap length, the maximum power density occurs in different $\mathrm{Bg}$ and $\lambda$. Table 2 shows maximum power density with corresponding $\mathrm{Bg}$ and $\lambda$. 
International Journal of Computer Science, Engineering and Applications (IJCSEA) Vol.1, No.6, December 2011

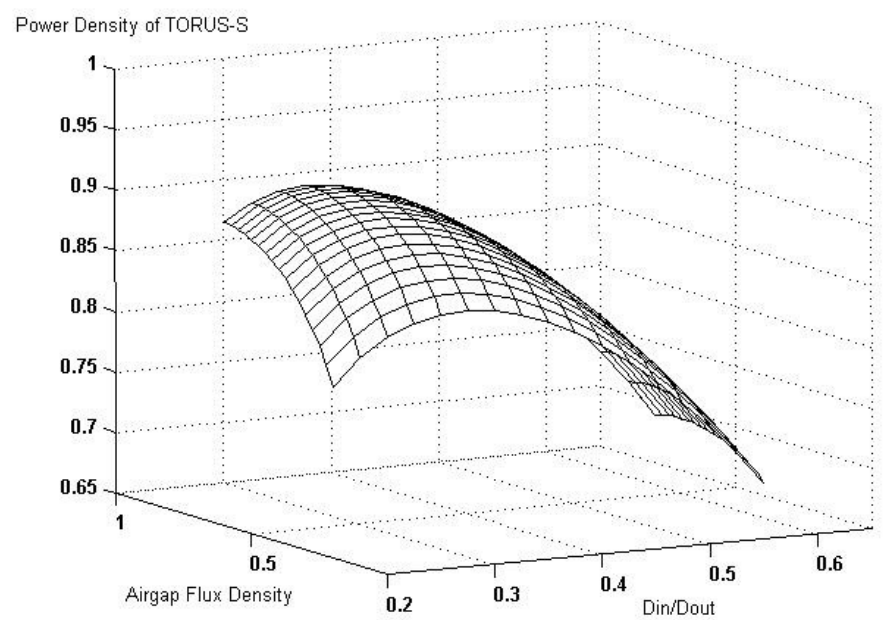

(a)

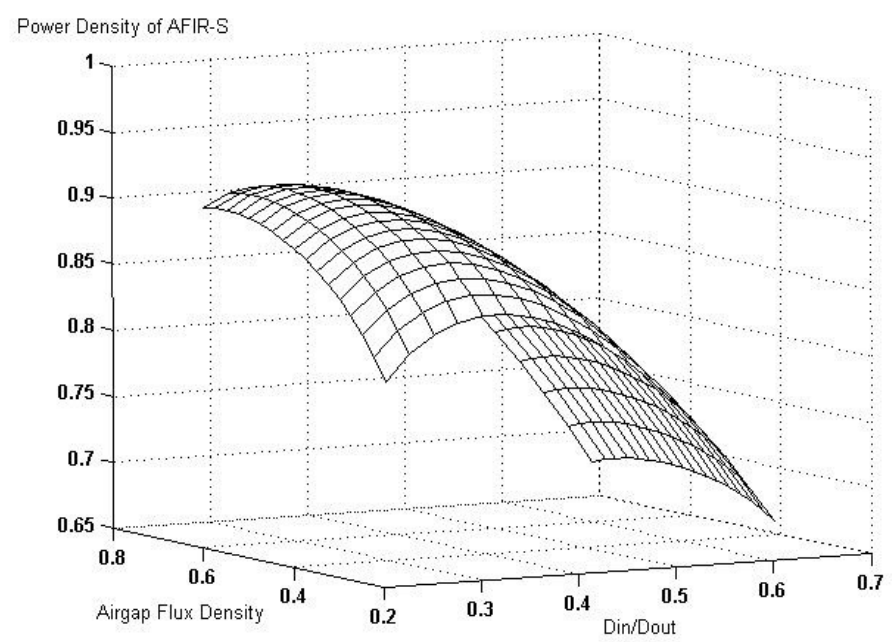

(b)

Figure3. Power density vs. air-gap flux density and diameter ratio for $A=20000(\mathrm{~A} / \mathrm{m}), g=1(\mathrm{~mm})$, $\mathrm{J}_{\mathrm{s}}=6000000\left(\mathrm{~A} / \mathrm{m}^{2}\right)$ a) TORUS-S b) AFIR-S

Table2. Maximum power density with corresponding Bg and $\lambda$

\begin{tabular}{|c|c|c|c|c|}
\hline Type & $\begin{array}{c}\mathrm{g} \\
(\mathrm{mm})\end{array}$ & $B g$ & $\lambda$ & $\begin{array}{c}\text { Maximum } \\
\text { power }\end{array}$ \\
\hline \multirow{4}{*}{$\begin{array}{c}\text { TORUS- } \\
\text { S }\end{array}$} & 1 & 0.585 & 0.29 & 0.92 \\
\cline { 2 - 5 } & 1.5 & 0.569 & 0.271 & 0.91 \\
\cline { 2 - 5 } & 2.5 & 0.565 & 0.271 & 0.89 \\
\hline \multirow{4}{*}{ AFIR-S } & 1 & 0.528 & 0.271 & 0.878 \\
\cline { 2 - 5 } & 1.5 & 0.518 & 0.261 & 0.925 \\
\cline { 2 - 5 } & 2 & 0.507 & 0.26 & 0.902 \\
\cline { 2 - 5 } & 2.5 & 0.518 & 0.251 & 0.87 \\
\hline
\end{tabular}


International Journal of Computer Science, Engineering and Applications (IJCSEA) Vol.1, No.6, December 2011

The maximum power density is changed by variation of air gap length. These variations are shown for the AFIR-S and TORUS-S generators for $A=20000(\mathrm{~A} / \mathrm{m}), J_{s}=6000000(\mathrm{~A} / \mathrm{m} 2)$ in figure4.

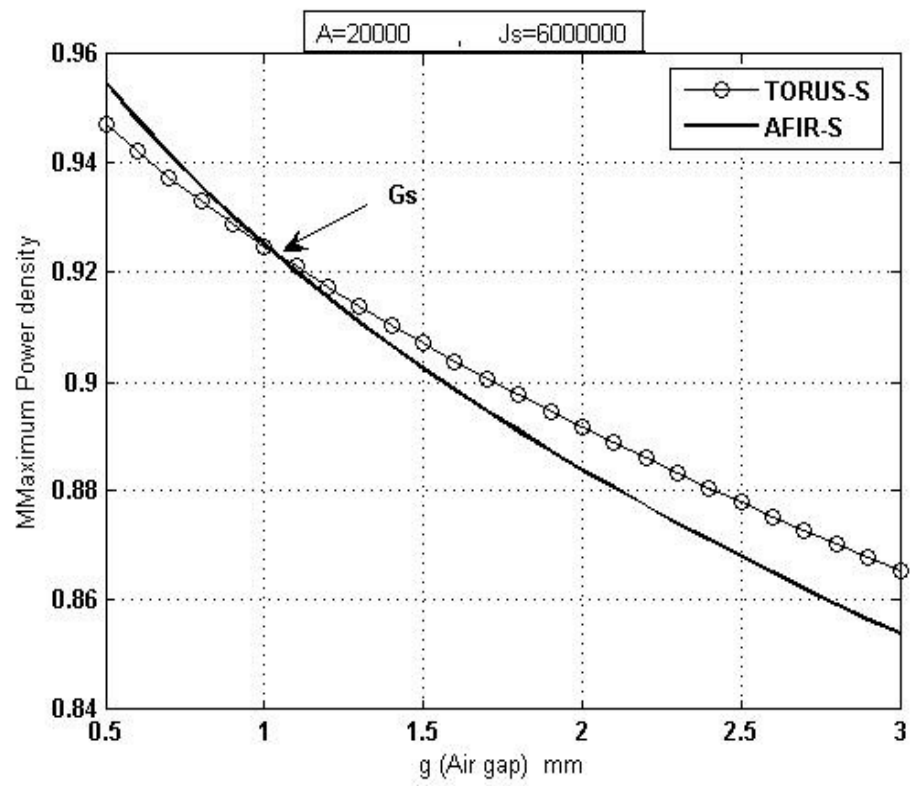

Figure4. Maximum power density AFIR-S and TORUS-S vs. air gap length

Maximum power density of two types of generators will be the same In special air gap length (Gs). According to presentation in Figure4, TORUS type of this generator has high power density in large air gap length. Should be noted that the value of Gs will change when the electrical loading ' $\mathrm{A}$ ' and current density 'Js' change.

Figure 5 shows the variation of the maximum power density as a function of air gap length in $\mathrm{A}=25000(\mathrm{~A} / \mathrm{m}), \mathrm{J}_{\mathrm{s}}=6000000\left(\mathrm{~A} / \mathrm{m}^{2}\right)$ for the AFIR-S and TORUS-S generators. Figure6 shows the variation of the maximum power density as a function of air gap length in $A=20000(\mathrm{~A} / \mathrm{m})$, $\mathrm{J}_{\mathrm{s}}=7000000\left(\mathrm{~A} / \mathrm{m}^{2}\right)$ for the AFIR-S and TORUS-S generators also. 
International Journal of Computer Science, Engineering and Applications (IJCSEA) Vol.1, No.6, December 2011

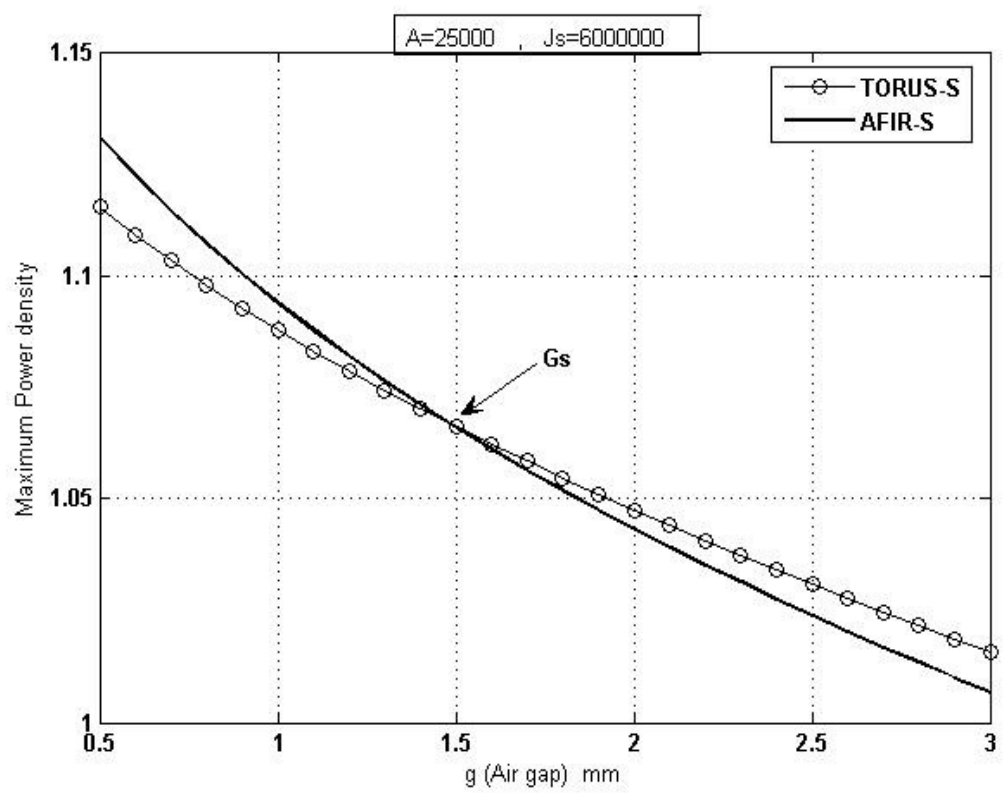

Figure5. Maximum power density AFIR-S and TORUS-S

Vs. air gap length

Figure5 shown that the point (Gs) is shifted to larger air gaps for AFIR-S type generator and this means that AFIR-S generator has higher maximum power density in smaller air gaps. Also, Figure6 shown that the point Gs is shifted to smaller air gaps for TORUS-S type generator and this means that TORUS-S generator has higher maximum power density in higher air gaps.

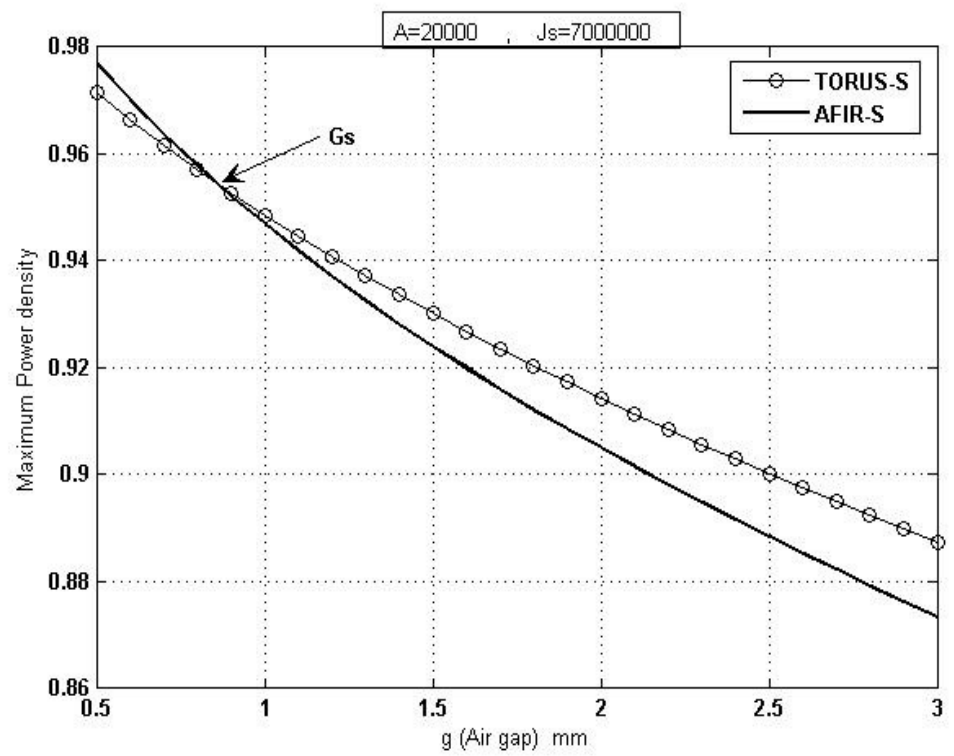

Figure6. Maximum power density AFIR-S and TORUS-S vs. air gap length 
International Journal of Computer Science, Engineering and Applications (IJCSEA) Vol.1, No.6, December 2011

\section{CONCLUSIONS}

The main goal of this paper has been introducing to double-Sided Axial Flux Slotted PM generators with maximum power density. There are two topologies for slotted double-sided AFPG generators.

The maximum power density is changed by different value of the air gap, electrical loading and current density. TORUS-S topology has high power density in high current density and low electrical loading. But, AFIR-S topology has high power density in low current density and high electrical loading.

\section{REFERENCES}

[1] J.R. Hendershot \& T.J.E. Miller, "Design of Brushless Permanent-Magnet Machines", Motor Design Books LLC; Second Edition, 2010.

[2] Chaker, Nadia; Salah, Ibrahim Ben; Tounsi, Souhir; Neji, Rafik, “ Design of axial-flux motor for traction application”, Journal of Electromagnetic Analysis and Applications (JEMAA), 2009.

[3] Martin Ranl f and Urban Lundin , "Finite Element Analysis of a Permanent Magnet Machine with Two Contra-rotating Rotors" , Electric Power Components and Systems, Volume 37, Issue 12 December 2009 , pages $1334-1347$

[4] Mahmood Joorabian, Amin Zabihi Nejad, Kaveh Malekian, “ Practical Aspects of Constructing A Wind Ironless Axial Flux Direct-drive generator”, Vol. 4. n. 1, pp. 235-241, 2009.

[5] Jacek F. Gieras,Rong-Jie Wang and Maarten J. Kamper, “Axial Flux Permanent Magnet Brushless Machines" Second Edition, 2008 Springer Science.

[6] Gholamian ,S.A, M. Ardebili and K. Abbaszadeh, 2008. Analytic and FEM Evaluation of Power Density for Various Types of Double-Sided Axial Flux Slotted PM Motors. International Journal of Applied Engineering Research, ISSN 0973-4562, Vol.3, No.6, pp. 749-762.

[7] N. A. Rahim, Hew Wooi Ping and M Tadjuddin, “Design of Axial Flux Permanent Magnet Brushless DC Motor for Direct Drive of Electric Vehicle”, PES2007, IEEE.

[8] Parag R. Upadhyay and K. R. Rajagopal, FE Analysis and Computer-Aided Design of a Sandwiched Axial-Flux Permanent Magnet Brushless DC Motor, IEEE Trans. Magn. 42 (2006) 3401 - 3403.

[9] F. Caricchi, F. Crescimbini, O. Honorati and R. Vivarelli, "Prototype of a Wind-Turbine DirectlyCoupled Axial-Flux PM Generator," in Proc. 1994Europ. Wind Energy Conf., pp. 492-499.

[10] M.R. Dubois, H. Polinder and J.A. Ferreira, "Axial and Radial-Flux PM Generators for Direct-Drive Wind Turbines," in Proc. 2001 Europ. Wind Energy Conf., pp. 1112-1115.

[11] Aydin, M.; Huang, S.; Lipo, T.A.; "Optimum design and 3D finite element analysis of nonslotted and slotted internal rotor type axial flux PM disc Machines”, Power Engineering Society Summer Meeting, 2001. IEEE Volume 3, 15-19 July 2001 Page(s):1409 - 1416 vol.3

[12] Aydin, M.; Surong Huang; Lipo, T.A.; "Design and 3D electromagnetic field analysis of non-slotted and slotted TORUS type axial flux surface mounted permanent magnet disc machines", Electric Machines and Drives Conference, 2001. IEMDC 2001. IEEE International2001 Page(s): 645 - 651. 
International Journal of Computer Science, Engineering and Applications (IJCSEA) Vol.1, No.6, December 2011

[13] S. Huang, J. Luo, F. Leonardi and T. A. Lipo, "A Comparison of Power Density for Axial Flux Machines Based on the General Purpose Sizing Equation", IEEE Trans. on Energy Conversion, Vol.14, No.2 June 1999, pp. 185-192.

\section{Author}

Sayyed Asghar Gholamian was born in Babolsar, Iran, in 1976. He received a B.Sc. degree in electrical engineering from K.N.Toosi University of Technology, Tehran, Iran in 1999 and a M.Sc. degree in electric power engineering (electrical machines) from university of Mazandaran, Babol, Iran in 2001. He also received the Ph.D degree in electrical engineering from K.N.Toosi University of Technology, Tehran, Iran in 2008. He is currently an assistant professor in the department of Electrical Engineering at the Babol Noshirvani University of Technology, Babol, Iran. His research interests include design, simulation, modeling and control of electrical machines

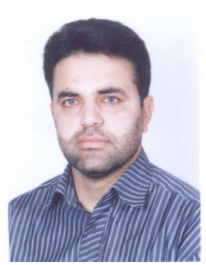

